\title{
Health surveillance during covid-19 pandemic
}

\author{
How to safeguard autonomy and why it matters
}

\author{
Rafael A Calvo professor ${ }^{1}$, Sebastian Deterding senior research fellow ${ }^{2}$, Richard M Ryan professor ${ }^{3}$ \\ ${ }^{1}$ Dyson School of Design Engineering, Imperial College London, London, UK; ${ }^{2}$ Digital Creativity Labs, University of York, York, UK; ${ }^{3}$ Institute for \\ Positive Psychology and Education, Australian Catholic University, Sydney, Australia
}

Societies are responding to the covid-19 pandemic at breathtaking speed. Many of these ad hoc responses will have long lasting consequences, and we must make sure that today's efforts do not threaten our future wellbeing.

The most consequential transformations may come from new health surveillance technologies that use machine learning and automated decision making to parse people's digital footprints, identify those who are potentially infected, trace their contacts, and enforce social distancing. Some have argued that such digital contact tracing could be more effective in controlling the epidemic than mass quarantine.

The Israeli government, for example, authorised the repurposing of an anti-terror phone tracking programme, trawling the location histories of its whole population to monitor and enforce self-isolation of people who tested positive. Israel's health ministry has since launched a mobile app allowing citizens to check whether they have crossed paths with anyone infected and need to self-isolate. ${ }^{2}$

In China, two big providers of mobile payment systems, Alipay and WeChat, released apps that combine users' health, location, and financial data to generate a personal infection risk rating. Government and businesses are using these technologies to decide whether to allow someone to access shops, transport, or public spaces. ${ }^{3}$

US government and state agencies are talking to companies such as Google, Facebook, and controversial startup Clearview AI about using location data mining or facial recognition to trace infected people and to monitor and enforce isolation. ${ }^{4}$ Around the globe, governments are rapidly following in implementing digital contact tracing of people with covid-19. ${ }^{5}$

\section{Surveillance creep}

One obvious concern is the high risk of false positive results generated by unreliable, biased, or non-transparent algorithms. Another is "surveillance creep," when surveillance developed for a limited purpose, such as fighting a pandemic or filming traffic violations, becomes used in ever more pervasive and permanent ways. Scholars and activists are already warning that much of the surveillance we accept today as "exceptional means for exceptional times" is here to stay. ${ }^{6}$

Beyond potential injustices and compromised civil rights, surveillance also has important psychological consequences. Decades of data show that individuals and societies can only thrive in environments that satisfy basic psychological needs, including autonomy - a sense of having volition and choice in your actions. ${ }^{7}$ Surveillance can engender a sense of being controlled and be experienced as thwarting autonomy, with negative effects on motivation and wellbeing. ${ }^{89}$ It can also spur people to try to evade surveillance and reassert their autonomy. South Korea's use of apps to publicise the movements of people with covid-19 has, for example, raised fears it might lead people to avoid being tested.

\section{Protecting wellbeing}

How can we design the health surveillance and AI tools needed to control covid-19 and future pandemics so they don't backfire or affect future wellbeing?

Research on the psychology of surveillance in other areas of healthcare offers helpful clues. Some patients with prostate cancer are offered active surveillance instead of immediate prostatectomy and radiation therapy. Treatment occurs when signs of disease progression appear in regular biopsies or clinical reviews. Researchers found that a strict health surveillance regime did not negatively affect psychological wellbeing when patients understood and endorsed its value. ${ }^{10}$

In the UK the NHS is developing an app that will automate covid-19 contact tracing, following China, Israel, and Singapore. Notably, however, the UK's deployment will be opt-in, and data will be kept private. The development team assessed the ethical concerns and concluded that an opt-in, privacy preserving design would best support "both reducing the number of cases and enabling people to continue their lives in an informed, safe, and socially responsible way. It offers the potential to achieve important public benefits whilst maximizing autonomy."11

More broadly, a key challenge for designers and engineers developing health surveillance systems is to align products with 
the values of those under surveillance and to communicate to wider society both these underlying values and the reasons for surveillance. Again, health psychology can provide evidence to guide the design of interventions that support patient autonomy, ${ }^{12}$ and ethical frameworks for AI are increasingly aligning with this principle. ${ }^{14}$

The ethical questions raised by health surveillance will only increase. Often, they are framed as a zero sum trade-off between security and privacy. But the psychology of autonomy suggests a productive alternative-when both sides endorse wellbeing as the jointly valued goal, health surveillance can be a positive sum game, both effective and chosen freely.

Competing interests: The BMJ has judged that there are no disqualifying financial ties to commercial companies. The authors declare the following other interests: RAC works with a variety of commercial companies including Google and IESO Health. SD works with a variety of commercial companies, including the Helmholtz Centre for Infection Research. RMR works with a variety of commercial companies. This work is unrelated to the topic of this editorial. The BMJ policy on financial interests is here: https://www.bmj.com/sites/default/files/attachments/resources/ 2016/03/16-current-bmj-education-coi-form.pdf.

Provenance and peer review: Not commissioned; not externally peer reviewed.

1 Ferretti L, Wymant C, Kendall M, et al. Quantifying dynamics of SARS-CoV-2 transmission suggests that epidemic control and avoidance is feasible through instantaneous digital contact tracing. medRxiv 2020.03.08.20032946 [Preprint]. 10.1101/2020.03.08.20032946
2 Winer S. Health ministry launches phone app to help prevent spread of coronavirus. Times of Israel 2020 Mar 20. https://www.timesofisrael.com/health-ministry-launches-phoneapp-to-help-prevent-spread-of-coronavirus/

3 Mozur P, Zhong R, Krolik A. In coronavirus fight, China gives citizens a color code, with red flags. New York Times 2020 Mar 19.

4 Grind K, McMillan R, Wilde Mathews A. To track virus, governments weigh surveillance tools that push privacy limits. Wall Street Journal 2020 Mar 23. https://www.wsj.com/ articles/to-track-virus-governments-weigh-surveillance-tools-that-push-privacy-limits11584479841

5 Privacy International. Tracking the global response to covid-19. 2020. https:// privacyinternational.org/examples/tracking-global-response-covid-19

6 French M, Monahan T. Disease surveillance: how might surveillance studies address covid-19? Surveill Soc 2020;18:1-11. 10.24908/ss.v18i1.13985 .

7 Ryan RM, Deci EL. Self-determination theory: basic psychological needs in motivation, development, and wellness. Guilford Publications, 2017.

8 Plant RW, Ryan RM. Intrinsic motivation and the effects of self-consciousness, self-awareness, and ego-involvement: an investigation of internally-controlling styles. $J$ Pers 1985;53:435-49. 10.1111/j.1467-6494.1985.tb00375.x.

9 Jensen JM, Raver JL. When self-management and surveillance collide: consequences for employees' organizational citizenship and counterproductive work behaviors. Group Organ Manage 2012;37:308-46. 10.1177/1059601112445804.

10 Carter G, Clover K, Britton B, etal . Wellbeing during active surveillance for localised prostate cancer: a systematic review of psychological morbidity and quality of life. Cance Treat Rev 2015;41:46-60. 10.1016/j.ctrv.2014.11.00125467109

11 Valentino-DeVries J. Translating a surveillance tool into a virus tracker for democracies. New York Times 2020 Mar 1. https://www.nytimes.com/2020/03/19/us/coronavirus-locationtracking.html

12 Gillison FB, Rouse P, Standage M, et al . A meta-analysis of techniques to promote motivation for health behaviour change from a self-determination theory perspective. Health Psychol Rev 2019;13:110-30. 10.1080/17437199.2018.1534071 30295176

13 Peters D, Calvo RA, Ryan RM. Designing for motivation, engagement and wellbeing in digital experience. Front Psychol 2018;9:797. 10.3389/fpsyg.2018.00797 29892246

14 Floridi L, Cowls J, Beltrametti M, etal . Al4People —an ethical framework for a good A society: opportunities, risks, principles, and recommendations. Minds Mach (Dordr) 2018;28:689-707. 10.1007/s11023-018-9482-5 30930541

Published by the BMJ Publishing Group Limited. For permission to use (where not already granted under a licence) please go to http://group.bmj.com/group/rights-licensing/ permissions 